HISPANICA43 (1999)

\title{
Mentalidad conversa en Mateo Alemán
}

\section{MAKIYAMA Hironobu}

Se cree que Mateo Alemán era converso. Hay varias razones para afirmarlo.

Se considera que Alemán era descendiente de Alemán Pocasangre quemado por la Inquisición. Un documento contemporáneo le califica tajantemente de judío y señala su relevante posición económica y social como mayordomo de Sevilla: "Quintos, el que aora es del Marqués, fue de un judío, mayordomo de Sevilla, hereje quemado, dicho alemán poca sangre" ${ }^{11}$.

De las profesiones que ejercían Mateo Alemán y su familia, se desprende un tufillo judío.

Su padre Hernando era médico- cirjano y ocupó el puesto como tal en la Real Cárcel de Sevilla. Su tío Juan practicaba la misma profesión hasta caer víctima de la peste cuando atendía a los enfermos en un hospital sevillano. No olvidemos que el mismo Mateo iba a seguir esta carrera, aunque la dejó en 1568 al terminar el cuarto curso de la Universidad de Alcalá sin ejercerla nunca en su vida. Así la medicina era la profesión preferida por la familia Alemán. Es bien notorio que era una de las profesiones más trípicas y tradicionales de la raza judía.

Además, entre las profesiones que ocupaba Alemán, nos llama la atención el trabajo relacionado con la recaudación de impuestos. Ya sabemos que ese oficio era ocupado frecuentemente por los judíos en otro tiempo.

Alemán intentó viajar al Nuevo Mundo en dos ocasiones: una vez a Perú en 1582, y otra vez a México en 1607. Mientras el primer intento no llegó a efectuarse por alguna razón desconocida, aunque obtuvo la licencia de la salida, su segundo intento, sí se efectuó, y no volvió jamás a su patria. En los trámites para estos viajes se observan algunas irregularidades que nos hacen dudar de su limpieza de sangre.

En abril de 1607, el novelista regaló una casa que tenía en Madrid a Pedro de Ledesma, secretario de la Real Consejo de Indias. Un mes después, como si 
hubiera sido poco el obsequio anterior, se le añadió el derecho de imprimir la segunda parte del Guzmán de Alfarache y el San Antonio de Padua. Al mes suiguiente, Alemán recibió la licencia de viaje a Nueva España. Estas dádivas pródigas del escritor a la persona encargada de otorgar las licencias de pasajes a las Indias nos huelen a sobornos para romper algunas barreras que dificultaban su viaje, las cuales pueden ser las disposiciones que prohibían a los cristianos nuevos la embarcación al Nuevo Mundo.

Del motivo de su emigración nada se sabe. El primir intento, Alemán pensaba establecerse como mercader en Perú. En 1607, cuando decidió su emigración a México, la situación era diferente: aquel hombre de treinta y cuatro años se convirtió en un anciano de casi sesenta años. Alemán, a esta edad, ¿qué buscaba en el Nuevo Mundo?

Se sabe que al lado de los emigrantes típicos (aventureros, segundones, criminales, etc.) se encontraban los conversos que obtenían permisos de viajes falseando la genealogía. Además de que se cotizaba su talento en el comercio y la administración en los países de los conquistadores, la emigración les servía de escape y refugio de las molestias causadas por su sangre en España. ¿Acaso Mateo Alemán, en la última etapa de su vida, buscaba el refugio y la paz en en el Nuevo Mundo como tantos otros conversos que emprendían el viaje transatlántico desesperados de la morbosa situación de su patria?

Naturalmente, tenemos que actuar con cautela ante el tema del linaje del novelista hasta que aparezcan los documentos que lo demuestren directamente, pero creemos que hay mucha posibilidad de que Alemán perteneciera al linaje de los conversos.

Ahora bien, las actitudes, las sensibilidades y el pensamiento que caracterizaban a los conversos se encuentran frecuentemente en el Guzmán y otras obras de Alemán. Así pues, vamos a ver algunas de estas expresiones que son los frutos de la mentalidad que llamamos conversa.

\section{Búsqueda de la sangre y la identidad.}

Guzmán sale de viaje con el fin de conocer a sus parientes. Así aclara: "Alentábame mucho el deseo de ver mundo, ir a reconocer en Italia mi noble parentela"(p.146) ${ }^{2)}$. Por lo tanto, cuando oía la noticia del reclutamiento para Italia, 
el deseo de conocer su linaje paterno le ponía inquieto "con crueles ansias" , pensando que era buena ocasión para su deseo: mis deseos - dice- "me espoleaban a hacer este viaje por conocer mi sangre y saber quiénes y de qué calidad eran mis deudos" (p.314). No parecía, sin embargo, que pudiera efectuarlo por falta de medios económicos. Afortunadamente el robo de 2500 reales le hizo efectuar el viaje a Italia. Al fin, Guzmán pudo llegar a Génova, pero los parientes no aparecieron a darle la bienvenida al niño roto y haraposo. Y cuando apareció su tío era sólo para hacerle una burla pesada que le dejó rencores profundos y le condujo a la venganza. Siete años después cuando Guzmán volvía a aquella ciudad rico y bien vestido, por fin pudo cumplir su deseo de largos años, esta vez, con toda facilidad. Dice: "mis deseos antiguos de saber de mí, por no morir con aquel dolor, habiendo andado por aquellas partes (...)a pocas vueltas hallé padre y madre y conocí todo el linaje" (p.683).

Ahora bien, lo interesante es observar aquí la transformación que introduce el autor en el objetivo y significado del viaje de Guzmán a Génova. Nótese que las expresiones "reconocer mi noble parentela","conocer a mi sangre y saber quiénes y de qué calidad eran mis deudos" " "mis antiguos deseos de saber de mí"manifiestan el cambio progresivo en los objetivos del protagonista. Parece revelarnos poco a poco su verdadera preocupación. El viaje de Guzmán tenía por objeto, más que la búsqueda de los parientes, la búsqueda de sí mismo: su sangre y su identidad. Así pues, la visita de Génova puede ser una expresión de la inquietud que el autor sentía por la sangre y la genealogía, cuya indagación enmienda a otro converso, el protagonista de la novela ${ }^{3)}$.

\section{Cambio de apellidos y deseo de anonimato.}

A la salida del viaje, Guzmán compuso un nuevo nombre con la combinación del apellido materno y el lugar de su génesis, argumentando así:"para no ser conocido no me quise valer del de mí padre; púseme el Guzmán de mi madre y Alfarache de la heredad adonde tuve mi principio" (p.145). Parece que el abandono del apellido paterno de Guzmán era una medida defensiva contra la sociedad en que la familia sufría"notables afrentas"(p.110) por la causa de su padre. Esta actitud de Guzmán se asemeja a la que tomaron muchos conversos.

En realidad, el cambio de apellidos, junto con el abandono de la tierra natal, era 
una de las medidas que los conversos utilizaban para confundirse entre los cristianos viejos borrando las pistas genealógicas. Diego de Hermosillo, entre muchos antisemitas, critica esta táctica de los judíos reconciliados y sus descendientes: "para mí tengo por cosa sospechosa que los hijos mayores dejen el apellido del padre y se arreen del de la madre, que lo hacen por cautela, porque acabe y olvide el apellido"4).

Cuando volvía de Italia, Guzmán pasaba por la Alcalá tan apacible que por poco decidió vivir allí. Pero pronto abandonó la idea y decidió marcharse a Madrid, ya que le atraía más la vida anónima que sólo las grandes ciudades le aseguraban. Guzmán manifiesta la razón de su traslado:"Nadie se conoce, ni aun los que viven de unas puertas adentro. Esto me arrastró, allá me fui" (p.756).

El deseo de la vida anónima y la preocupación por el descubrimiento de la identidad tienen su profunda raíz en la mente de Guzmán, con la cual tal vez el autor se identifica. En una degresión en que alaba la vida picaril, Guzmán dialoga consigo y expresa su deseo de pasar la vida tranquilamente sin ser molestado por nadie ni ser objeto de la conversación de los corrillos: "estate como estás, Guzmán amigo; séanse enhorabuena ellos la conseja del pueblo, nunca se acuerden de ti” (p.275); "Eso te importa ir solo que acompañado, apriesa que de espacio, riendo que llorando, corriendo que trepando, sin ser notado de alguno" (p.276). Aquí sería conveniente citar las palabras de Benito Brancaforte, que comenta la psicología de Guzmán, galán de Toledo: "Como se sabe, el converso en la sociedad española de la época tenía una gran ansia de anonimato: no ser conocido suponía la posibilidad de ser dejado en paz por los murmuradores" ${ }^{5)}$.

\section{Reclamación de la igualdad del hombre en sangre y linaje.}

Guzmán expresa frecuentemente la igualdad del hombre en varios aspectos. Se pueden sacar con facilidad algunos pasajes que se refieren a la igualdad del hombre : "Tenganos Dios de su mano para no caer en otras semejantes miserias, que todos somos hombres" (p.124); "Y aunque de pícaro, creo que todos somos hombres y tenemos entendimientos" (p.266); "A mí me parece que son todos los hombres como yo, flacos, con pasiones naturales y aun estrañas" (p.481); "Entendí que, aunque habló con religiosos, tocaba en común a todos (...)que también eres miembro de este cuerpo místico, igual con todos en sustancia, aunque no en 
calidad" (pp.267-268).

La insistencia en el tema señala que se trata de una de las mayores preocupaciones del escritor. Francisco Rico dice al respecto: "Y es el caso que si en algo insiste Mateo a lo largo de toda su obra, con especial ahínco y en contra de la práctica social coetánea, es en la fundamental paridad humana(...). En buena medida, el Guzmán de Alfarache no hará sino eso, raer la pintura para dejar al descubrierto la 'tela' común" 6).

Entre las igualdades que Alemán pide hay la igualdad de sangre y linaje, la cual se encuentra en la frase del narrador de la novela intercalada de Ozmin y Daraja.El clérigo se sorprende de la hostilidad de los campesinos contra la nobleza, y se lamenta de que ocurran este tipo de discordias entre los seres humanos, y acaba predicando el amor y la fraternidad entre los hombres con la argumentación de que todos somos de la misma cosa (la carne. la sangre, el origen, la fe...):"mas hombres racionales, los unos y los otros de un mismo barro, de una carne, de una sangre, de un principio, para un fin de una ley, de una doctrina, todos en todo lo que es hombres tan una misma cosa, que todo hombre ame a todo hombre" (p.234).

La doctrina cristiana enseña que todos provienen del mismo origen, todos están llamados a pertenecer al cuerpo místico, pero esta idea no regía en aquella sociedad en cuanto a los conversos. Ante esta realidad, los escritores conversos no dejan de reclamar la igualdad evocando dicha doctrina fundamental del cristianismo. Uno de ellos, Fray Luis de León hace referencias insistentes sobre la igualdad de linaje:"Y a la verdad, casi todas ellas reduzen a ésta, que es ser generosos y nobles todos de un mismo linaje" ; "Y assi todos son hechura y nascimiento del cielo, hermanos entre sí y hijos todos de Cristo" ${ }^{7)}$.

Ahora bien, diecioho años después de la muerte de Fray Luis, el doctor Alvaro Picaño denuncia estos pasajes a la Inquisición y llama esta reclamación de la igualdad, el lenguaje común de conversos:"quiere que todos sean iguales (...), éste es lenguaje común de todos a quien toca esta mala raza, y se opone a todo esto a la nobleza y la sangre limpia, y más a los Santos Tribunales de la Inquisición" ${ }^{8)}$. Entonces, la insistencia en el tema de la igualdad en las obras de Alemán, ino podría ser una de las expresiones producidas por este "lenguaje común" de la "mala raza"? 


\section{Temor y odio al vulgo.}

Alemán escribe un prólogo al vulgo, en donde descarga su desprecio y su crítica contra él. Increpa al "enemigo vulgo" : "cuán mordaz, envidioso y avariento eres; qué presto en difamar, qué tardo en honrar, qué cierto a los daños, qué incierto en los bienes, qué fácil de moverte, qué difícil en corregirte" (p.93) Entre estas características terribles del vulgo, su ignorancia y falta de juicio se ven destacadas en otros lugares. En el prólogo al discreto lector se fefiere al vulgo como sinónimo de ignorantes: "Tal he salido del proemio pasado, imaginando en el barbarismo y número desigual de los ignorantes"(p.93). También en la narración de Guzmán se ven otros ejemplos que destacan estas características:"Mas cuando te quieras dejar llevar de la opinión y voz del vulgo, que siempre es la más flaca y menos verdadera, por serlo el sujeto de donde sale"(p.121); llega "la ignorancia del vulgacho a querer todos emparejarse" (p.403).

Ahora bien, A.Porqueras Mayo caracteriza la figura del vulgo que aparece en el teatro español "como una fuerza impersonal que representa la opinión pública, 'el qué dirán', siempre temible porque juzga rápida y por apariencias" 9). Esta concepcíon del vulgo es también aplicable a nuestra novela. La murmuración y la opinión del vulgo tenían mucha fuerza en esta sociedad y eran protagonistas en los asuntos de las honras. En la larga digresión sobre las honras, Guzmán señala la participación del vulgo en el juicio de las honras, y la considera como uno de los mayores tormentos que disturban la vida sosegada: "Y si con el vulgo se ha de caminar, ella es uno de los mayores tormentos que a quien con quietud quiere pasar su carrera le puede dar la fortuna ni padecer en esta vida" (p.262).

Así pues, los conversos tenían razón al temer al vulgo. B.Brancaforte dice a propósito del prólogo al vulgo:"Además del tópico literario (...) se transparenta aquí una realidad inmediata: el odio y miedo del converso hacia el grupo más peligroso para él, el amorfo e ignorante vulgo, siempre propenso a la caza de judíos por motivos económicos como también por fánatismo religioso" ${ }^{10)}$.

\section{Obsesión de la asechanza y la murmuración}

El tema de la asechanza y la murmuración pulura en el mundo novelístico del Guzman hasta tal punto que prueba ser la verdadera obsesión del autor. Guzmán expresa una irritación ante una sociedad llena de desconfianza y hostilidad en que 
todos viven en asechanza y en busca de los puntos débiles de los otros: "todos vivimos en asechanza los unos de los otros, como el gato para el ratón o la araña para la culebra, que hallándose descuidada, se daja colgar de un hilo y, asiéndola de la cerviz, la aprieta fuertemente, no apártandose della hasta que con su ponzoña la mata" (p.280). Repite la misma idea más adelante cuando destaca la inutilidad del saber humano contra la asechanza maliciosa: "Todo y cada uno por sus fines, quieren usar del engaño, contra el seguro dél, como declara una empresa, significada por una culebra dormida y una araña, que baja secretamente para morderla en cerviz y matarla, cuyo lema dice: 'No hay prudencia que resista al engaño'. Es disparate pensar que pueda el prudente prevenir a quien le acecha" (p.563).

Aquí nos conviene recordar el retrato del autor insertado en las ediciones de sus obras autorizadas por él mismo. Allí el novelissta aparece señalando con el dedo índice un emblema en el que la araña está en acecho colgando de un hilo para matar una serpiente, y el lema latino reza: $A b$ insidijs non est prodentia. Así pues, dichas citas explican precisamente este emblema, que es, según Samuel Gili Gaya,"una de las imágenes predilectas del autor, y de las más representativas de su pensamiento" ${ }^{11)}$.

En las frases citadas, Guzmán enfatiza la universalidad y la omnipotencia de la asechanza. Efectvamente, muchos personajes de la novela presentan esta actitud de asechanza, y otros, al contrario, sufren por ella. El genovés está en acecho de lo que pasa con la Marcela falsamente enferma (p.132); el mesonero acecha la ocasión para servir la carne de muleto por la de ternera (p.172); Fabia rehusa la tercería de Guzmán para su amo embajador diciendo: "todos pienso que me acechan" (p. 536); el enamorado Claudio acecha la vida de Dorotea y su marido (p.718); Dorido, a dos amigos suyos (p.440); los ladrones, el paradero de los baúles de Guzmán (p. 566); acechan un platero (p.347), Sayavedra (p.634), un caballero (p.690) y el propio Guzmán (p.751). La asechanza no permanece sólo a la actividad humana: acechan también la mona (p.516), el demonio (p.717), la venganza (p.689), el daño (p.723) y la ballesta (p.816).

La exposición nos permite hasta qué punto estaban arraigados el sentimiento de persecución y la preocupación por la asechanza en la mentalidad de nuestro novelista.

Ahora bien, a pesar de la declaración de la inutilidad de la precaución contra la 
asechanza, Guzmán no deja de amonestar a los que mantienen esta actitud casi inquisitorial para que cuiden de sí mismo dejando la pesquisa de lo ajeno:"Pónese la otra en su ventana, y el otro a su puerta en acecho de de la casa de su vecino, por saber quién salió antes del día o cuál entró a media noche, qué trajeron o qué llevaron, sólo por curiosidad, y de aquello averar o inferir sospechas, por ventura son de cosas nunca hechas. Hermano, hermana, quítate de ahí" (p.619). Como se sabe, la asechanza produce la sospecha, y ésta crea la murmuración. Sobre la murmuración, la mala lengua y "el qué dirán" Alemán tiene mucho que decir. Se caracteriza la murmuración: "La mormuración, como hijo natural del odio y de invidia, siempre anda procurando cómo manchar y escurecer las vidas y virtudes ajenas" (p.205).

Varios personajes de la novela tropiezan con la murmuración maliciosa. La madre de Guzmán, ya casada con el genovés, sufría "la idolatría del qué dirán, la común opinión, la voz popular, que no le sabían otro nombre sino la comentadora"(p.141). La salida apresurada de Daraja de la plaza donde se celebraba la justa, provocó la sospecha y la murmuración de los espectadores, que "se admiraron cómo de alguna cosa no recibía contento y aun lo murmuraban, sospechando cada uno aquello con que mejor se casaba su malicia" (p.231). Las protagonistas de dos narraciones intercaladas, Dorotea y una viuda anónima, temían la murmuración que pudiera ensombrecer su honra. Guzmán tenía que dejar la cómoda situación de la casa del embajador por la murmuración divulgada por una criada, y su enojo con ella acabó en la acusación y desconfianza en las mujeres en general: "iVed lo que destruye una mala lengua de mala mujer que, sin salvarse a sí, difamó la casa de sus amos y descompuso la nuestra!” (p.570).

\section{Crítica de la limpieza de sangre.}

Entre los múltiples aspectos de las honras, ocupan un puesto relevante las honras fundadas en la genealogía y la limpieza de sangre. Los estatutos de limpieza de sangre y las actividades inquisitoriales contribuyeron a divulgar y exagerar esta actitud de saber y hablar de las vidas y linajes ajenos. Un religioso, contemporáneo de Alemán, se lamenta de la pesquisa genealógica de sus paisanos:"Cuántos sin ser Flos Sanctorum tratan de vidas ajenas, y haciéndose becerros de los linajes, a nadie perdonan sin reparar en atropellar honras y famas" ${ }^{12}$. 
Joseph H.Silverman señala el ambiente inquisitorial de la sociedad representado por las frases como "saber vidas ajenas", "espulgar la sangre", "desterrar los muertos", etc., que se encuentran en las obras de Fray Antonio de Guevara, Fray Luis de León, Beato Alonso de Orozco, Juan de Zabaleta, Baltasar Gracián, nuestro Alemán, Quevedo y Cervantes: "El sentido de saber vidas ajenas en estos contextos y tantos otros que podían citarse nos revela algo sobre la propensión inquisitorial de la sociedad en que vivía Cervantes mientras esribía el Quijote, propensión que de mil maneras ya explícitas ya indirectas se manifestaba en la literatura picaresca del momento" ${ }^{13)}$.

En nuestra novela, Guzmán, cuando habla de sus padres, critica la manía genealógica de sus coetáneos comparando de manera despectiva a los que se dedican este tipo de pesquisas con la hiena que se nutre desterrando los cuerpos muertos: "Y aunque a ninguno conviene tener la propiedad de la hiena, que se sustenta desterrando cuerpos muertos, yo aseguro, según hoy hay en el mundo censores, que no les falten coronistas" (p.106).

El tema del linaje es también motivo de acusación pública cuando hay riñas o discusiones, y Guzmán señala algunos casos. Los alcaldes y los escribanos se acusan mutuamente de sospecha de sangre: "los unos a los otros desterraron los abuelos, diciendo quiénes fueron sus madres, no perdonando a sus mujeres proprias y las devociones que habían tenido"(p.181). La queja de Guzmán contra su primera esposa se convierte en la maldición de las mujeres en general, que denuncia públicamente el linaje de su marido: "No quieres que lo desentierren y desentiérrasle tú hasta los huesos de todo su linaje" (p.783).

También una criada, que pesquisa y divulga todas las actividades de su amo, puede revelar las costumbres sospechosas de su pobre patrón que mete una porción de tocino en el caldo para evitar los rumores sobre su sangre, como ocurre al dominé Cabra del Buscón: dice "que atais el tocino para echarlo dentro y con sólo un cuarto dél hacéis toda la semana, porque se vuelve a sacar y se guarda" (p. 811).

No falta la referencia directa a la limpieza de sangre en la novela. El galateo recuerda con nostalgia el tiempo que pasaba como mendigo, y enumera las ventajas que tiene este estado, una de las cuales es la libertad de las preocupaciones de la limpieza de sangre, que hacen maníacos a sus coetáneos. El narrador denuncia la 
actitud perversa de la gente no mendiga, que alega su limpieza censurando la falta de los otros. Guzmán habla en su lugar: “Cómo descubriré al otro su falta, para que quien oyere que la murmuro piense que yo no la tenga?” (p.391). Guzmán niega esta actitud de honrarse con las deshonras ajenas cuando presenta la historia nada honrosa de sus padres: "pues nace de viles y bajos pensamientos tratar de honrarse con afrentas ajenas, según de ordinario se acostumbran: lo cual condeno por necedad solemne de siete capas como fiesta doble" (p.106).

Ahora bien, para probar oficialmente la limpieza de sangre se necesitan testimonios que apoyen la cristiandad de los antecedentes del probante. En la mayoría de los casos, estos testimonios se basan en el examen oral de los testigos. De ahí, el dinero, la amistad o la enemistad pueden desviar la información. Estos testigos falsos son también el objeto de la crítica severa de Guzmán:"Digamos algo de un testigo falso, cuya pena deja el pueblo amancillado y a todos es agradable gustando de su castigo por lo grave de su delito" (p.674). Guzmán dice que los jueces y los escribanos sirven de testigos a los pobretones por poco dinero y saca luego el caso de un testigo labrador que jura tener ochocientos años en la probanza de la limpieza de su señor. El viejo de poco entendimiento contesta a los jueces que le preguntan por qué jura así:"Porque así conviene a servicio de Dios y del Conde, mi señor" (p.675). Estos episodios señalan lo absurdo y falso del sistema.

Pero el más temible y preocupante es el caso contrario, un testigo falso que niega la limpieza de un aspirante, ya que le priva la honra y le quita los cargos y puestos que su limpieza promete ocupar:"Testigos falsos hay: las plazas están llenas, por dinero se compran, el que quisiere de balde, busque parientes encontrados, que por sustentar la pasión dirá contra todo la generación y déstos nos libre Dios, que son los que más nos dañan" (p.676) ${ }^{14)}$.

Hemos visto las características típicas de los conversos en la novela de Alemán. Como nuestra opinión, Antonio Domínguez Ortíz reconoce los rasgos peculiares que caracterizan a los conversos en sus escritos: "Todos los rasgos característicos de esta clase social se encuentran reunidos en el famoso novelista sevillano Mateo Alemán; no es difícil descubrir en sus escritos quejas mal encubiertas que son el eco de amargas reflexiones inspiradas en las consecuencias que para él tenía el llevar en sus venas sangre tachada de infecta" ${ }^{15}$.

En contra de esta opinión, hay quienes niegan rotundamente la influencia de su 
condición de converso sobre su creación literaria, Uno de ellos, Eugenio Asensio dice: "En el campo literario es problema peliagudo el marcar de 'hebraico' un mode de sensibilidad, un sesgo de pensamiento. (...)¿Qué parte de la novela de Mateo Alemán no encuentra plena claridad en las corrientes de su época y en su peculiar carácter? ${ }^{16)}$. A.A.Parker también adopta la misma postura: "No hay nada en el Guzmán de Alfarache que necesite ser explicado por el origen judío de su autor" ${ }^{17}$.

Tenemos que precisar el problema. Nosotros tampoca creemos que Alemán expresara su creencia o pensamiento judío en sus obras ni que el origen judío como raza o casta ejerciera alguna influencia sobre él. Ya expusimos nuestra opinión afirmativa sobre la sinceridad del cristianismo del escritor ${ }^{18)}$. El problema converso "no era, en absoluto, de índole racial, sino social y, secundariamente, religioso" como dice Francisco Márquez Villanueva ${ }^{19)}$. Lą injusticia o persecución causada por su sangre heredada era lo que irritaba a Alemán y muchos otros conversos. Así pues, estamos al lado de A.A.Sicroff, que contesta estos intentos de minimizar o anular la influencia 'hebraica' en la literatura española: "Mateo Alemán (...) was perhaps one who gave more evidence in his writing of his converso situation than of the Judaism buried away in his Jewish origins" ${ }^{20}$.

\section{Notas}

1) Fidel Fita, 1889, "Los conjurados de Sevila: Relación de Cristóbal Nuñez “, Boletín de la Real Academia de la Historia 15, p.560. Sobre sus detalles, cf. nuestoro artículo, 1993, "Mateo Alemán y los problemas del apellido y del linaje", Hispanofila 107, pp.1-3 de la separata.

2) Para las citas del Guzmán, utilizamos la edición de Francisco Rico, 1983, Barcelona, Planeta.

3) Esto quiere decir que el novelista describió a Guzmán como converso. El origen levantisco de la familia paterna de Guzmán llevó a Marcel Bataillon a la conclusión de que era una de tantas familias judías que hubieron de exiliarse huyendo de la persecución antisemita durante la expulsión de 1492 o quizás antes de ella (1969, Pícaro y picaresca, Madrid, Taurus, p.225). Por otra parte, Donaldo McGrady señala que la cobardía y el afeminamiento del padre de Guzmán eran considerados como características típicas de los judíos en aquel tiempo (1968, Mateo Alemán, New York, Twayne, p.122).

4) 1901, Diálogo de los pajes, ed. A.Rodríguez Villa, Madrid, Imprenta de la Revista Espoñola, p.47. 
5) 1979, "Introducción" a su edición del Guzmán, Madrid, Cátedra, I, p.39.

6) “Apéndices” a su edicion del Guzmán, pp.941-942.

7) 1982, De los nombres de Cristo, ed. Cristóbal Cuevas, Madrid, Cátedra, p.374.

8) Marcel Bataillon, 1966, Erasmo y España, México, Fondo de Cultura Económica, p.767, nota 77 .

9) 1972, Temas y formas de la literatura española, Madrid, Gredos, p.120

10) 1996, su edición del Guzmán, Madrid, Akal, p.59, nota 1.

11) 1975, su edición del Guzmán, Madrid, Espasa Calpe, II, p.54, nota.

12) Fray Diego de la Vaga, 1612, Paraíso de la gloria de los Santo, Barcelona, II, p.98 citado por Luys Santa Marina, 1949, La vida cotidiana de nuestoros clásicos, sequnda serie, Barcelona, CSIC, p.21.

13) 1978 , "Saber vidas ajenas: un tema de vida y literatura y sus variantes cervantinas", Papeles do Son Armadans 267, P.201.

14) Además de estos temas, sobre la defensa de los conversos, cf. nuestro artículo citado en la nota 1, pp.5-7, y sobre la animadversión contra el campesinado, cf. nuestro artículo, 1996. “Sociedad conflictiva en Ozmin y Daraja del Guzmán de Alfarache, Hispánica 40, pp. 99- 102.

15) 1974, Orto y ocaso de Sevilla, Sevilla, Universidad de Sevilla, pp.99-100.

16) 1976, La España imaginado de Américo Castro, Barcelona, El Albir, pp.61-62.

17) 1971, Los picaros en la literatura, Madrid, Gredos, p.49.

18) Cf. nuestro artículo, 1998, "Postura religiosa de Mateo Alemán” , Hispánica 42,pp.61 -69 .

19) 1980 , El problema de conversos, cuatro puntos cardinales”, Hispánica judaica, I, History, Barcelona, Puvill, p.61.

20) 1972, "Américo Castro and his critics: Eugenio Asensio" , Hispanic Review 40, p.12. 
〈Resumen〉

\section{Mentalidad conversa en Mateo Alemán}

\section{MAKIYAMA Hironobu}

Se cree que Mateo Alemán era converso. Se considera que nuestro novelista era descendiente de Alemán Pocasangre, un judío quemado por la Inquisición. La medicina a que se dedicaba la familia Alemán y la recaudación de impuestos que el escritor ocupaba unas veces eran las profesiones preferidas por la raza judía. También el traslado de Alemán a México origina unas sospechas en torno a su sangre.

Esta condición del converso influye mucho en sus escritos. En efecto, la mentalidad que caracterizaba a los conversos se percibe en su Guzmán de Alfarache y otras obras suyas. Eran los frutos de esta mentalidad los temas como la búsqueda de la sangre y la identidad, el cambio de apellidos y el deseo de anonimato, la reclamación de la igualdad del hombre en sangre y linaje, el temor y el odio al vulgo, la obsesión de la asechanza y la murmuración, y la crítica de la limpieza de sangre. 